\title{
Confidences de Salon
}

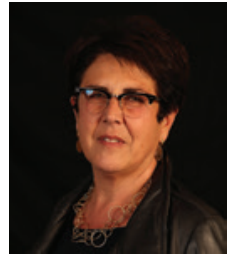

Maria R. Bonsignore is Head of the ERS Clinical Physiology, Sleep and Pulmonary Circulation Assembly, and an Associate Professor at DiBiMIS, University of Palermo, Palermo, Italy. She has a research interest in respiratory sleep medicine, with a focus on obstructive sleep apnoea. She is also involved in basic aspects of exercise physiology, in particular, airway cell composition and circulating progenitors in athletes.

\section{Did you always dream of being involved in medical research/healthcare?}

My father was a brilliant pulmonologist, and I was raised in an environment in which science and excellence were of great value, but the real start was at University of California, San Francisco, CA, USA, working on pulmonary oedema in Norman Staub's laboratory. One day he told me "Marisa, you got the spark!" From then on, I have always done research.

\section{What is the best advice you had when you were starting your professional career?}

Try to always consider "the big picture". A young investigator in a big laboratory initially does not know all the parts of the puzzle, and the tiny piece of his research project is often hard to understand and does not stand by itself. Putting things in the right context helps to build up the resilience necessary for the job.

\section{What advice would you give someone at the beginning of their professional career?}

I think we all end up doing what we like best. Every student, resident or fellow should follow his heart and passion. Our task is not to force him or her; just understand what might work better and discuss opportunities. Respect is key.

\section{What has been the greatest change to make a difference in your field in your lifetime?}

Cite as: Confidences de Salon: Maria R. Bonsignore. Breathe 2017; 13: 61-62
Respiratory sleep medicine is a relatively young field; 35 years ago, only a few physiologists and clinicians were interested in sleep disordered breathing. Now, it is a major part of clinical respiratory medicine, and both technology and knowledge have greatly improved the care of our patients. The development of noninvasive ventilation has changed positively the prognosis of patients with neuromuscular disorders, and this was a major advance.

\section{What do you foresee being the next great thing and what do you foresee as being the biggest challenge in your field in the next 10 years?}

Immunomodulatory treatment could change the prognosis of lung cancer and I really hope for new treatments for this disease. I also expect to see more research about gender-related issues and integrated care models for the ageing population. The biggest challenge in sleep medicine is recognition of subgroups of patients at high risk in whom treatment of sleep disordered breathing might make a difference. Right now, we are facing high numbers of subjects with respiratory events during sleep, but are not really sure about which of them should be treated. 


\section{What is your favourite scientific breakthrough from any field?}

I am fascinated by the response to hypoxia and by the physiology of mitochondria, the small intracellular organelles with their own DNA that are responsible for energy production. Being a cardiologist before being a respiratory physician, I am interested in exercise physiology and, again, mitochondria are my favourites.

\section{How do you see the future of the ERS?}

The enlargement of ERS as a global scientific society is a challenge, but we are getting ready for it. The ERS has a superb office with very smart people working to make the dream of a global ERS come true. In this regard, ERS educational activities are really important to strengthening the seeds of a global ERS, with the HERMES projects, courses and examinations. We are working hard to make them work.

\section{When are or were you happiest?}

I am happy when I can travel and see the beauty of the world, especially if I succeed in disconnecting completely from home and work. I enjoy the small things of life: reading a nonmedical book, the beach, family and friends. Owning my dog Bric was a very happy experience, and I hope I will have another dog in the future.

\section{What do you dislike most?}

I hate being under pressure and try to work well in advance to comply with deadlines. Unfortunately, this is not enough, and high pressure is an unpleasant component of daily life. Nevertheless, I recognise a little pressure helps productivity and deadlines are essential to get things done.

\section{Who has been your greatest inspiration?}

Norman C. Staub was my mentor, a scientist full of wit, curiosity and practical solutions. In his laboratory, I learned the methodology of research and had the urge to move forward every day. I still refer to what I learned from him 30 years ago.

\section{Whom would you most like to thank?}

Luc Balant was the Chair of the EU COST Domain Committee of Biomedicine and Biomedical Sciences when served as the Italian representative on the Committee. I have to thank him for his lessons on how to deal with other people on controversial matters, since I am not very diplomatic.

\section{What do you consider your greatest achievement?}

Running the Bay to Breakers race in San Francisco in 2007. I had never done it when I was living there, and it was marvellous to run through the city and see Golden Gate Park again!

\section{Who are your favourite authors?}

Marguerite Yourcenar, Oriana Fallaci, Andrea Camilleri and Oscar Wilde.

\section{Who are your heroes in real life?}

The people who are able to make other people happy; for example, those playing the piano in airports.

\section{Where would you most like to live?}

I enjoy living in Sicily but could live everywhere; better if it is a place with warm weather.

\section{What is or was your greatest journey?}

A trip to Iran in 2009 was the most interesting and surprising travel experience I had in my life. A beautiful country and a beautiful people.

\section{What qualities do you appreciate most in your colleagues?}

Intellectual honesty.

\section{What is your personal motto?}

If I can do it, everyone can do it.

\section{What do you consider to be your strengths and weaknesses?}

In Italy, creativity is a way of life and I hope it is one of my strengths. Among weaknesses, I do not really like clinical work, although challenging cases are interesting. I also hate administrative work. 